\title{
ANTHROPOGENIC THREAT TO THE DESERT TORTOISE (GOPHERUS AGASSIZII): LITTER IN THE MOJAVE DESERT
}

\author{
Andrew D. Walde ${ }^{1,3}$, Meagan L. Harless ${ }^{1}$, David K. Delaney ${ }^{2}$, and Larry L. Pater ${ }^{2}$
}

Key words: desert tortoise, Gopherus agassizii, threat, litter, Mojave Desert, California.

Anthropogenic threats to reptile populations within desert ecosystems in the Southwest take many forms. As humans have become more prevalent in the desert, other associated impacts have increased, such as the presence of ravens and feral dogs, use of off-road vehicles, construction of roads and fences, and dumping of garbage and litter (Boarman 2002). Effects of garbage and litter on reptiles are poorly understood mainly because of the rarity of observing what are primarily chance encounters. Furthermore, there are few places where such observations can be published and that limits both the dissemination of information to a broader audience and the critical discussion and assessment of these issues as threats. However, our review of the literature revealed isolated instances of litter as a source of concern for some reptiles. Snakes and lizards have died, received severe lacerations, or experienced reduced mobility from entanglement with litter (Groves and Groves 1972, Herrington 1985, Dean et al. 2005).

In addition, while not garbage or litter per se, plastic netting used for erosion control and exclusion of birds and other wildlife is emerging as an important threat to snake populations due to entanglement (Stuart et al. 2001, Barton and Kinkead 2005). The resistance of this material to degradation makes it a continuing threat long after it is discarded (Stuart et al. 2001). Leatherman (1996) documented the death of a San Diego horned lizard (Phrynosoma cononatum blainvillii) that was caught in an erosion control blanket, and Engeman et al. (2004) observed numerous carcasses of Texas tortoises (Gopherus berlandieri) that apparently died from becoming entangled in the woven material at the bottom of fences. Also, reproductive success of American alligators (Alligator mississippiensis) is diminished when litter is used as nesting material (Coulson and Coulson 1993). There is limited information on the interaction of freshwater turtles with litter; however, freshwater turtles have been documented with severe shell deformities caused by entanglement with litter (Odum 1985, McLeod 1994, Dietz and Ferri 2003). In sharp contrast to the scanty information available for most reptiles, there are numerous reports from all over the world of sea turtles interacting with and ingesting litter. These reports document death, esophageal and stomach blockage, decreased gut performance, as well as gut volume displacement from an array of litter including, but not limited to, plastic bags, styrofoam, monofilament fishing line, and net fragments (Balazs 1985, Starbird and Audel 2000, Barreiros and Barcelos 2001, Mascarenhas et al. 2004).

Little is known about the effects of garbage and litter on the desert tortoise (Gopherus agassizii), a species listed by federal agencies as threatened (USFWS 1990a, 1990b). Herein, we report on balloons, a widespread type of litter, as a potential threat to the desert tortoise.

During daily radio-tracking we observed that one of our research tortoises appeared to have ingested some ribbon. At 1735 hours PST on 23 August 2004, an adult male appeared to be foraging. The observer quietly approached from behind to limit disturbance and saw that a section of white ribbon with a partial piece of balloon was extended in front of the tortoise on the ground. At first it appeared as if the ribbon were simply caught between the shell, legs, 
and body of the tortoise, so the observer attempted to remove it. As the tortoise retracted and moved its head, it became evident that the ribbon was coming from its mouth. Gentle pulling on the ribbon caused the tortoise to clamp its mouth shut not allowing the ribbon to be pulled out. Securing the tortoise and applying gentle, even pressure to the ribbon caused the tortoise to extend its head and open its mouth repeatedly, allowing a small length of the ribbon to be extracted each time. In all, $108 \mathrm{~cm}$ of ribbon was extracted from the tortoise. The ribbon had undigested Schismus barbatus and unidentifiable, partially digested vegetative material stuck to it in places, indicating that it had been quite far down the digestive passageway. We don't know if the tortoise intentionally bit at the balloon or if the balloon was accidentally ingested because it had been tangled in vegetation that was consumed.

Our study site was located approximately $40 \mathrm{~km}$ northeast of Barstow, California, in San Bernardino County, $8.5 \mathrm{~km}$ from the closest paved road. There were very few houses in the area, the closest being $7.6 \mathrm{~km}$ away. Our study site represented a remote section of the Mojave Desert far removed from anthropogenic activity. The area is presently designated as critical habitat (USFWS 1994) as part of the Superior-Cronese Critical Habitat Unit. The vegetation community was dominated by creosote bush (Larrea tridentata) and white bursage (Ambrosia dumosa), typical of the Mojave Desert. To quantify the potential threat that balloons pose to desert tortoises, we counted the number of balloons encountered. Picking up garbage and litter when encountered during the previous 2 years of research at the study site had effectively cleared the area of any old balloons. Researchers then began recording numbers of balloons encountered during daily work at the study site, making note if each balloon was fresh or old so that we could quantify new balloon arrivals. A total of 178 new balloons arrived at the study site between March 2005 and November 2005. The origin of most balloons is unknown because they were either blank or printed for generic events such as Mother's Day, graduation, or birthdays. However, 1 balloon had lettering indicating that it was from a drug company anniversary party. Our internet sleuthing revealed that the party had occurred in San Diego, California (>270 km away), although the balloon may have been transported closer to the study area by a participant. Another balloon we found was from a fund-raising balloon release at a school in Huntington Beach, California, >200 $\mathrm{km}$ away. We observed that balloon materials, such as mylar or latex for balloons and nylon for ribbons, are slow to break down in the environment, so there is potential for balloon litter to accumulate.

Little published information is available on litter in the desert. However, Michael Connor (personal communication) stated that employees and volunteers pick up hundreds of balloons each year at the Desert Tortoise Research Natural Area (DTNA), Kern Co., California. Berry (2002) noted that "balloons make up most of the litter" on a long-term study plot at the interior of the DTNA. While doing other work, we have also noted that balloon litter is present in other areas of the desert, suggesting that our site and the DTNA are not novel, or acting as balloon accumulation points. In fact, Dr. Kristin Berry has been recording balloon litter as 1 type of trash on $>30$ long- and short-term study plots, because she recognized the potential threat. Her records reveal that this form of trash is present at all study areas, but is much more common on sites close to the southern California metropolitan area (Berry, unpublished data, U.S. Geological Survey files). Furthermore, observations of desert tortoises interacting with anthropogenic litter are not novel. Burge (1989) documented a desert tortoise losing its leg after catching it in the string of a balloon. The same author documented the presence of foil and glass chips in tortoise scats and noted that tortoises do eat foreign objects that can cause obstructions (Burge 1989). Our observation of a tortoise consuming balloon litter supports these statements. These observations of desert tortoises consuming foreign objects are similar to MacDonald and Mushinsky’s (1988) observation of manufactured materials in the scats of gopher tortoises (Gopherus polyphemus).

In a critical review of all available data and documentation of potential threats to desert tortoises, Boarman (2002) included a section titled Garbage and Litter, in which he states that most garbage in the desert is localized and that there are no data to suggest that litter 
is widespread or a major problem to the desert tortoise. Based on results from balloon surveys, our observation of a tortoise partially ingesting a balloon, and Burge's (1989) observation of a tortoise losing a limb from entanglement in balloon string, we suggest that balloons may pose a real threat to desert tortoises. Evidence that a tortoise died from entanglement or ingestion of litter may be overlooked during infrequent surveys because balloon material might either blow away or be removed or consumed by an animal scavenging the dead tortoise. We suggest that further investigation is warranted into the risks posed by garbage and litter to tortoises and other reptile populations.

Funding and field support for this project was provided by USACERL. In addition, we thank Mickey Quillman, DPW Environmental, Fort Irwin, California, for providing additional logistical and financial support. Field work could not have been completed without assistance from Jill Adams, Nick Bieser, Leslie Bol, Brett Degregario, Chris Howey, Miki Kern, Philippe Rosenfeld, and Joel Strong. We thank Michael Connor, Kristin Berry, William Boarman, and 2 anonymous reviewers for discussion and/or comments on earlier versions of this manuscript. Research was conducted under USFWS recovery permit TE066452-1 and CDFG Memorandum of Understanding for Scientific Collecting Permit \#802005-03.

\section{Literature Cited}

BALAZS, G.H. 1985. Impact of ocean debris on marine turtles: entanglement and ingestion. Pages 387-429 in R.S. Shomura and H.O. Yoshida, editors, Proceedings of the Workshop on the Fate and Impact of Marine Debris, 26-29 November 1984, Honolulu, Hawaii. NOAA Technical Memorandum NMFSISWFC-54.

Barreiros, J.P., AND J. BARCElos. 2001. Plastic ingestion by a leatherback turtle Dermochelys coriacea from the Azores (NE Atlantic). Marine Pollution Bulletin 42:1196-1197.

Barton, C., AND K. Kinkead. 2005. Do erosion control and snakes mesh? Journal of Soil and Water Conservation $60: 33 \mathrm{~A}-35 \mathrm{~A}$.

Berry, K.H. 2002. Preliminary field reports from five long-term desert tortoise study sites and notes on other health and disease projects, spring 2002. Draft Progress Report, 21 July 2002. U.S. Geological Survey.

BoARman, W.I. 2002. Threats to desert tortoise populations: a critical review of the literature. U.S. Geolog- ical Survey, Western Ecological Research Center, Sacramento, CA.

Burge, B.L. 1989. What goes up must come down. Massive balloon releases are a potential threat to tortoises and other wildlife. Tortoise Tracks 10:4.

Coulson, J.O., AND T.D. Coulson. 1993. Alligator mississippiensis (American alligator). Nest material. Herpetological Review 24:58.

Dean, C.L., H.T. Smith, R.M. Engeman, and W.E. MEShaKA, JR. 2005. Leiocephalus carinatus armouri (northern curly-tailed lizard). Entanglement in human-made materials. Herpetological Review 36: 179-180.

DietZ, R., AND D. FERRI. 2003. Chelydra serpentina (common snapping turtle). Deformity. Herpetological Review 34:56.

Engeman, R.M., M.J. Pipas, and H.T. Smith. 2004. Gopherus berlandieri (Texas tortoise). Mortality. Herpetological Review 35:54-55.

Groves, J.D., AND E.M. Groves. 1972. An unusual accident involving an eastern king snake, Lampropeltis getulus getulus. Herpetological Review 4:14.

Herrington, B. 1985. Another reason for herpetologists to pick up their beer cans. Herpetological Review 16:113.

Leatherman, B.M. 1996. Phrynosoma coronatum blainvillii (San Diego horned lizard). Conservation. Herpetological Review 27:80.

MaCDOnALD, L.A., AND H.R. Mushinsky. 1988. Foraging ecology of the gopher tortoise, Gopherus polyphemus, in a sandhill habitat. Herpetologica 44:345-353.

Mascarenhas, R., R. Santos, and D. Zeppelini. 2004. Plastic debris ingestion by sea turtle in Paraíba, Brazil. Marine Pollution Bulletin 49:354-355.

MCLEOD, D. 1994. Observations of growth after injury in the slider turtle, Trachemys scripts elegans. Herpetological Review 25:116-117.

Odum, R.A. 1985. Pseudemys scripta elegans (red eared slider). Deformity. Herpetological Review 16:113.

Starbird, C., And H. Audel. 2000. Dermochelys coriacea (leatherback sea turtle). Fishing net ingestion. Herpetological Review 31:43.

Stuart, J.N., M.L. Watson, T.L. Brown, and C. Eustice. 2001. Plastic netting: an entanglement hazard to snakes and other wildlife. Herpetological Review 32:162-164.

[USFWS] U.S. Fish and Wildlife Service. 1990a. Endangered and threatened wildlife and plants; determination of threatened status for the Mojave population of the desert tortoise. Federal Register 55:1217812191.

1990b. Assessment of biological information for listing the desert tortoise as an endangered species in the Mojave Desert. Pre-decision document. National Ecology Research Center, Fort Collins, CO.

1994. Endangered and threatened wildlife and plants; determination of critical habitat for the Mojave population of the desert tortoise. Federal Register 59:5820-5866.

Received 7 November 2005 Accepted 10 May 2006 